\title{
Freeman's Syntactic Criterion for Linkage
}

\section{DAVID HitchCOCK}

\author{
Department of Philosophy \\ McMaster University \\ Hamilton, Ontario \\ Canada L8S $4 K 1$ \\ hitchckd@mcmaster.ca
}

\begin{abstract}
Freeman's syntactic criterion for linked argument structure (Freeman 2011) is often readily applicable, captures intuitively linked structures, and implies that refuting a single premiss of a linked argument suffices to refute the argument. But one cannot sharply separate analysis from inference evaluation in applying it, whether an argument satisfies it can be uncertain, it undergenerates cases where refuting one premiss suffices to refute an argument, some arguments satisfying it can be easily rescued if a single premiss is refuted, and Freeman's underlying account of probative relevance is dubious.
\end{abstract}

Résumé: Le critère syntaxique de Freeman employé pour déterminer quand les prémisses d'un argument sont liées (Freeman 2011) est souvent facilement applicable, identifie intuitivement les prémisses liées, et implique que réfuter une seule prémisse liée suffit à réfuter l'argument. Mais l'application de ce critère ne distingue pas nettement l'analyse de l'évaluation d'une inférence. C'est parfois discutable si un argument remplit ce critère syntaxique; son application sous-estime le nombre de cas où la réfutation d'une prémisse suffit à réfuter un argument; il $\mathrm{y}$ a des arguments qui répondent à ce critère et qu'on peut facilement rétablir si une seule prémisse est réfutée; et l'explication sous-jacente de la pertinence est douteuse.

Keywords: argument structure, convergence, James B. Freeman, linkage, refutation, Stephen N. Thomas.

\section{Introduction}

The linked-convergent distinction introduced by Stephen Thomas (1977) has become a standard topic in introductory textbook treatments of argument structure. See for example Freeman (1993, pp. 86-106), Ennis (1996, p. 39), LeBlanc (1998, pp. 3236), Fisher (2001, pp. 32-38), Bailin and Battersby (2010, pp. 42-44), Govier (2010, pp. 37-39), Vaughn and MacDonald (2010, pp. 95-96), and Groarke and Tindale (2013, 115-119). 


\section{David Hitchcock}

Informally, the distinction is clear enough. Where more than one premiss is offered in direct support of a conclusion, the premisses sometimes work together to support it and are in this sense linked, whereas at other times distinct subsets of them offer independently relevant reasons that "converge" on the conclusion. Theoretically, however, the distinction is vexed. Scholars have made the informal idea precise in a number of ways, to each of which other scholars have produced counter-examples. Walton (1996, pp. 109-182) offers a useful analysis, which could easily be extended to cover contributions of the subsequent two decades. Noting the apparent theoretical intractability of the distinction, Geoff Goddu has argued $(2007,2009)$ that it should be abandoned, since the purposes it serves can be accomplished without it.

In his Argument Structure: Representation and Theory (Freeman 2011), James Freeman has refined his criterion for linked argument structure, defended it against others' objections, and argued for the usefulness of the linked-convergent distinction. Freeman's criterion is distinctive in being syntactic rather than semantic, and is the culmination of more than two decades of reflection on the topic (Freeman 1988, 1991, 1993). It therefore merits careful consideration.

\section{Freeman's project}

Freeman understands the linked-convergent distinction as a distinction between two types of structures in single-inference multi-premiss arguments. In a convergent structure, the premisses are partitioned into jointly exhaustive subsets, each of which is presented as independently relevant to the conclusion. But there is a single inference from the subsets taken together to the conclusion. As a paradigm case, Freeman gives the example:

(1) The economy will be resurgent next year because all the leading economic indicators are up, the public mood is confident, and business needs to make significant capital improvements in the near future. (Freeman 2011, p. 16)

Here each of the three premisses is presented as independently relevant to the conclusion that the economy will be resurgent next year. Taken together, the premisses make a stronger case for the conclusion than each does by itself. From a dialectical 
point of view, each successive premiss can be construed as a response to a challenger who asks, "Can you give me another reason?"

In a linked structure, on the other hand, two or more premisses are only relevant to the conclusion in combination. If any one of them is taken "off the table", the remaining premisses in the linked structure are no longer relevant to the conclusion. As a paradigm case, Freeman gives the example:

(2) Prices for goods in general will rise because demand for goods in general is increasing. If demand for goods in general increases, then prices for goods in general will rise. (Freeman 2011, pp. 14-15)

Here the second sentence can be understood dialectically as the proponent's response to a challenger who might ask, "Why is that [the first premiss-DH] relevant to the claim you allege it to support?"

A single argument can have both linked and convergent structures, when one (or more) of the reasons that converge in support of the conclusion consists of linked premisses. An example would be a modification of example 1 that added an explanation of the relevance of the third premiss:

(3) The economy will be resurgent next year because all the leading economic indicators are up, the public mood is confident, and business needs to make significant capital improvements in the near future (capital investment being a contributor to economic growth).

Here the parenthetical addition links with the original third premiss to constitute a two-premiss reason presented as independently relevant to the conclusion.

Freeman's conception of convergence should be distinguished from the conception of convergent arguments as independent arguments with a shared conclusion-a conception found for example in Michael Hoffmann's argumentdiagramming software AGORA (http://agora.gatech.edu/) and in (Selinger 2014), who seems to have been influenced by the ambiguous presentation of the concept of convergence in (Reed et al. 2007). Freeman makes abundantly clear (Freeman 2011, pp. 107-113) the difference between a convergent structure with two or more allegedly independently relevant reasons in a single one-inference argument and a structure with multiple independ-

(C) David Hitchcock. Informal Logic, Vol. 35, No. 1 (2015), pp. 1-31. 


\section{David Hitchcock}

ent arguments for a common conclusion. However, he offers no guidance on how one can tell whether an argumentative text with two or more premisses offered in direct support of a conclusion consists of two or more independent arguments for that conclusion or rather of a single argument, whose main structure may be either linked or convergent. Hoffmann gives the following advice to users constructing arguments using his argument diagramming software:

\footnotetext{
Anytime you want to add another reason to an existing argument, you need to decide whether this reason can justify your claim independently from the reason you already have or whether this is a reason that can justify your claim only in connection with the already existing reason. (http://agora.gatech.edu/learn/arguments)
}

He calls reasons of the first kind "independent reasons" and of the second kind "co-dependent reasons." His distinction, like the pragma-dialectical distinction between multiple and coordinatively compound argumentation (van Eemeren and Grootendorst 1991, pp. 73-82), corresponds to Freeman's distinction between independent arguments and single arguments with more than one premiss. Hoffman's single arguments with co-dependent reasons, like the coordinatively compound argumentation of the pragma-dialectical approach, may have either linked or convergent structure. His advice to users of the AGORA software may help in interpreting ambiguous argumentative texts: if the premisses offered in direct support of a conclusion can be partitioned into reasons that are each sufficient to support the conclusion, treat these reasons as independent arguments for the conclusion. Textual indicators like the words 'further' or 'moreover' can also be a clue to the presence of independent arguments, but they may also signal independently relevant reasons in a single argument with convergent structure.

Freeman explicitly rejects three common criteria for linked structure: that premisses offered in support of a conclusion provide stronger support together than each does individually, that premisses individually do not entail the conclusion but augment one another, that the falsity of one premiss would undercut the force of the remaining premiss or premisses (Freeman 2011, p. 98). These properties hold not only for linked structures, he maintains, but also for many convergent structures.

Each of these three rejected criteria requires inference

(C) David Hitchcock. Informal Logic, Vol. 35, No. 1 (2015), pp. 1-31. 
evaluation for its application. In contrast, Freeman proposes that one identify the convergent and linked structures in a multipremiss single-inference argument at the analysis stage, independently of any evaluation. In this way, Freeman maintains, one will establish in advance which premisses of a singleinference component need to be refuted in order to refute that component. If some premisses are combined in a linked structure, then refuting just one of them is enough to refute that part of the argument. Identifying a linked structure thus saves labour at the evaluation stage. To get this labour-saving advantage, Freeman proposes a criterion whose application does not require inference evaluation, namely, the following syntactic criterion:

\begin{abstract}
An argument contains linked structure if and only if two or more premises of the argument directly support a conclusion and the leading principle or inference license of the subargument consisting of those premises and conclusion contains at least one mediating element. (Freeman 2011, p. 139)
\end{abstract}

The terms 'leading principle,' 'inference license' and 'mediating element' require explanation, as perhaps does the reference to 'the subargument.' The inference license of an argument is a general rule, possibly qualified, that permits drawing the conclusion from its premiss or premisses. The leading principle, first so labelled by Peirce $(1955 / 1880)$, is the articulation of this rule as a proposition. For example, the argument that, since Petersen is a Swede and most Swedes are non-Catholic, Petersen is probably a non-Catholic (Toulmin 1958, p. 109) has as its inference license the rule of the statistical syllogism: From " $\mathrm{x}$ is an $\mathrm{S}$ " and "most S's are P," you may infer, ceteris paribus, "x is probably P." The leading principle of the argument is that a given individual probably has a certain property if it belongs to a class whose members mostly have the property. By a mediating element, Freeman means an element occurring in at least two premisses of the inference rule but not occurring in the conclusion. In the statistical syllogism rule, the mediating element is the term variable 'S.' I will argue later that this element has to be a variable. By the subargument, Freeman means the part of the argument consisting of the conclusion, the two or more premisses and the inference license with at least one mediating element; he thus allows for the possibility that the whole argument may have additional premisses offered in direct support of the conclusion,

(C) David Hitchcock. Informal Logic, Vol. 35, No. 1 (2015), pp. 1-31. 
as in example 3 above, where the argument contains a linked structure consisting of the conclusion, the third and fourth premisses and the inference rule. If a multi-premiss single-inference argument does not contain independently relevant reasons, then the subargument with linked structure will be identical to the whole argument.

Freeman's criterion is an attempt to make precise the idea of joining in Thomas's metaphor of a linked structure. A mediating element that occurs in more than one premiss of an inference rule joins together the premisses in which it occurs. The resulting syntactic connectedness makes the argument refutable by refuting just one of the premisses, Freeman claims, since in that case the link is broken. He locates the mediating element or elements in the implicit rule of inference rather than in the explicit argument so as to avoid ambiguity of structure in hypothetical examples like the argument that it is raining, because it is raining and if it is raining, it is raining. However, he admits the notion of a mediating concept (p. 139, n. 5), which is the value of the mediating element in the explicit argument. For example, in the Petersen argument, the mediating concept is the concept of being a Swede, which is the value in that argument of the mediating element ' $\mathrm{S}$ ' in the argument's rule of inference.

It is important to realize, however, that the mere presence of a concept in two or more premisses but not in the conclusion does not in itself show that those premisses are linked. Freeman makes the mistake of assuming so, and thus misapplies his own criterion, in his discussion of the following argument:

(4) Knowledge is limited. Imagination is almost limitless. Therefore, imagination is more important than knowledge. (Freeman 2011, p. 156; quoted from Gratton 2002, p. 10)

Freeman proposes that we can interpret this argument as having as its inference rule: from " $x$ is limited" and " $y$ is not limited," one may infer " $y$ is more important than $x$." He claims that this is a two-premiss rule with a mediating concept, the concept of being limited. But the claim that the concept of being limited is a mediating concept in this rule of inference is false, and in fact reflects a category mistake. On Freeman's own conception, mediating concepts occur in explicit arguments, not in their implicit inference rules. A mediating concept in an argument is an instantiation of a mediating element in its rule of inference-a

(C) David Hitchcock. Informal Logic, Vol. 35, No. 1 (2015), pp. 1-31. 
mediating element, which therefore must be a variable (specifically, a variable occurring in more than one premiss of the rule but not in the rule's conclusion). On Freeman's interpretation, the concept of being limited is not a mediating concept in argument 4 , because it is not the instantiation of a variable in the argument's rule of inference.

To forestall misunderstanding, it should be noted that not all structures that are linked on Freeman's criterion are (presented as) deductively valid arguments. For example, the argument that Petersen is probably not a Catholic, because he is a Swede and most Swedes are non-Catholic, has linked structure but is presented as merely making the conclusion probable. The same is true of any statistical syllogism with a hedged conclusion. Arguments by analogy and inductive extrapolations that are presented as non-conclusive likewise have a linked structure even though they are not presented as deductively valid. Consider for example the argument: Sending military advisors has always in the past been a prelude to engaging in combat operations; Canada has sent military advisors to Iraq; so Canada will probably be engaged in combat operations in Iraq. This argument is most plausibly interpreted as having as its rule of inference: from "doing A has always in the past been a prelude to doing $\mathrm{B}$ " and " $\mathrm{x}$ has done A," you may infer "x will probably do B." This rule of inference has as a mediating element the action variable 'A,' so the argument comes out linked on Freeman's criterion. Similarly, with other arguments by analogy and inductive extrapolations whose conclusion is presented as supported nonconclusively.

Conversely, not all arguments that are (presented as) deductively valid come out as linked on Freeman's criterion. For example, conjunction introductions are deductively valid but convergent, because there is no mediating element in the rule of conjunction introduction: from $p_{1}$ and ... and $p_{\mathrm{n}}$, one may infer " $p_{1}$ and $\ldots$ and $p_{\mathrm{n}}$."

Although Freeman's criterion is syntactic rather than semantic, he takes it to be closest in spirit to the semantic criterion that Douglas Walton calls the Suspension/No Support test: "If one premise is suspended (not proved, not known to be true), the conclusion is not given any support." (Walton 1996, p. 120) In his textbook, Freeman proposed as a rough-and-ready intuitive test of linkage in a two-premiss single-inference argument the following "blocking test":

(C) David Hitchcock. Informal Logic, Vol. 35, No. 1 (2015), pp. 1-31. 
If we knew that just one of the premises were true and had no knowledge of the other, would we see why that premise was relevant to the conclusion? If we blocked the other premise completely out of our mind, would we see why the first still gave a reason for the conclusion? If the answer is yes, then the premises are convergent. If no, then they are linked. (Freeman 1988, p. 178; 1993, p. 101)

Walton (1996, p. 153) objects that this test wrongly classifies as convergent such standard examples of linked arguments as the following:

(5) If an action promotes the best interests of everyone concerned and violates no one's rights, then that action is morally acceptable. In at least some cases, active euthanasia promotes the best interests of everyone concerned, and violates no one's rights. Therefore in at least some cases active euthanasia is morally acceptable. (Copi and Cohen 1990, p. 20)

Copi and Cohen quote this argument as an example of a structure in which "premisses must work together to support their conclusion" and "neither of the two premisses supports the conclusion independently". But, according to Walton (1996, p. 153), if we suspend either premiss of this argument (i.e. regard it as not proved or not known to be true), it still seems that the remaining premiss gives some support to the conclusion. Although Walton does not explain why he thinks so, a plausible explanation for his judgment is that the suspended premiss might for all we know be true. In reply, Freeman makes clear that he means by blocking a premiss completely out of one's mind something stronger than regarding it as not proven or not known to be true. From his basic perspective of taking arguments to be products emerging from a dialectical context, Freeman supposes (2011, pp. 147-148) that the first premiss of the argument quoted by Copi and Cohen could be produced in response to an imagined challenger who might not see how the second premiss is relevant to the conclusion. Likewise, the second premiss could be produced in response to someone who might not see the relevance of the first premiss because they do not entertain the idea that some cases of active euthanasia might satisfy its antecedent. To block one of these premisses completely out of one's mind, then, is to take the perspective of the imag- 
ined challenger for whom the premiss is included, someone who has no idea that the premiss is true. Such a challenger, Freeman claims, would not see why the remaining premiss is relevant to the conclusion. So understood, Freeman's blocking test would better be called, he says, "the Suspension/No Reason in Itself test" (Freeman 2011, p. 148).

The blocking test is for Freeman an informal and intuitive rough guide to identifying convergent and linked structures. It is helpful pedagogically, he thinks, but it is not his fundamental position. His official criterion for linkage is the presence of a mediating element in the inference license of the sub-argument with linked premisses.

A significant feature of Freeman's account of linkage is a tripartite conception of the constituents of a single-inference argument:

For me, arguments are not individuated solely by their premises and conclusions, but minimally also by the warrant or warrants they instance to move from their premises to their conclusions. So, for example, an argument "P1, P2, therefore C" instancing a two-premise inference rule (in particular, a two-premise rule with a mediating element) is numerically distinct from an argument with the same premises and conclusion, where a one-premise inference rule conveys us separately from each premise to the conclusion. (Freeman 2011, p. 161)

An argument is identified not just by its premisses and its conclusion but also by the rule of inference that the author takes to license drawing the conclusion from the premisses-a rule that Freeman calls its "warrant." using a term introduced by Stephen Toulmin (1958). Freeman's tripartite conception of an argument resembles the tripartite conception extracted by Rolf George (1986) from the writings of Bolzano (1972/1837), according to which a single-inference argument is individuated by its premisses, its conclusion, and its "variands": the "constants tagged for substitution" (George 1986, p. 558). Such tripartite conceptions put a burden on arguers and reasoners to signal which rule of inference they are using, or in Bolzano's version to identify their variands. And they put a burden on addressees to pick up those signals and read them correctly.

Freeman makes clear that with a convergent structure there is no simple recipe for combining the support that each reason gives to the conclusion if its constituent premisses are

(C) David Hitchcock. Informal Logic, Vol. 35, No. 1 (2015), pp. 1-31. 


\section{David Hitchcock}

acceptable and it is in fact relevant. At least, he does so eventually. "If each premise gives a separate, additional reason," he writes at one point, "the probability of the conclusion given all of them should be the sum of the probabilities of each, or at least each reason should raise the probability" (Freeman 2011, p. 102). Here he opens the way to a quasi-algorithmic computation of the probability of the conclusion given the reasons collectively as a function of its probability given each reason separately. Later, however, he regards it as no objection to his account of convergence that one cannot take the strengths of support given by each independently relevant reason in a convergent argument and somehow combine them to get an evaluation of the overall strength of support given by the reasons together:

\footnotetext{
That we may see each premise independently relevant to a conclusion (or intended as independently relevant to the conclusion), in no way implies that in evaluating the argument we should determine the strength of each premise separately and "add" up the results... In determining whether the premises provide grounds adequate for the conclusion, we need to take the premises in combination. (Freeman 2011, pp. 158-159)
}

This position is much more reasonable than his earlier one. For there are cases where the strength of support given by a set of independently relevant reasons is less than the strength of support given by each of them alone. Pollock (1993, p. 574) gives the example of deciding what dish to order at a restaurant. It might count in favour of a particular dish that it includes pickles, which one likes. It might also count in favour of this dish that it includes ice cream, which one also likes. But the combination of pickles and ice cream might be distinctly unappetizing. Again, Pollock (1995, p. 102) imagines two testimonies to the same thing in a linguistic community where speakers tend to confirm each other's statements only when they are fabrications. In such a situation, the strength of support given by the two independently relevant testimonies together is less than the strength of support given by each of them separately.

\section{Advantages of Freeman's approach}

Freeman's syntactic approach to identifying linked structures avoids the repetition implicit in semantic approaches, a repeti-

(C) David Hitchcock. Informal Logic, Vol. 35, No. 1 (2015), pp. 1-31. 
tion that nullifies the supposed economy of effort at the evaluation stage. Consider for example the semantic test for linkage implicit in Stephen Thomas's test for convergence:

In a genuine convergent argument, the support given the conclusion by each distinct reason would be undiminished if the other (separate and independent) reason(s) were false; each separate reason would still support the conclusion just as well if the other (separate and independent) reason(s) were false. (Thomas 1977, p. 39; cf. Thomas 1981, p. 55; 1986, p. 61; 1997, p. 53)

Since Thomas takes linkage and convergence to be complementary structures, his corresponding test for linkage of two or more premisses is that falsification of any of them diminishes the support that each of the other premisses provides by itself to the conclusion. We could call this criterion "diminished support on falsification." To apply it, one has to judge the effect on the strength of support given by each premiss separately of the falsehood of each of its coordinate premisses. For a set of three premisses, applying Thomas's criterion thus involves six judgments of comparative inferential strength: whether the support given in itself by premiss 1 is diminished if premiss 2 is false, whether the support given in itself by premiss 1 is diminished if premiss 3 is false, and so on. If all six judgments are positive, meaning that the support given by each premiss is diminished if either of the other two premisses is false, then the three premisses are linked. At the evaluation stage, if one judges that one of the three premisses is in fact false, then one can conclude that support by the three premisses for the conclusion is diminished, in virtue of their linked structure. But the prior identification of the linked structure hardly makes evaluation quicker, because the process of identifying the linked structure has required one to make this judgment beforehand along with five similar other judgments.

A similar repetition is involved in other semantic tests that require one to determine the strength of support given by premisses in certain hypothetical circumstances: insufficient support on falsification, no support on falsification, diminished support on suspension (also known as elimination), insufficient support on suspension/elimination, no support on suspension/elimination (cf. Walton 1996, pp. 119-120).

These semantic tests have another weakness that Freeman's account avoids: they assume that the premisses being

(C) David Hitchcock. Informal Logic, Vol. 35, No. 1 (2015), pp. 1-31. 


\section{David Hitchcock}

tested for linkage do in fact support the conclusion if none of them is suspended or falsified. If the argument is a blatant non sequitur even if all the premisses are adequate, then the premisses automatically get classified as linked if the criterion for linkage is insufficient or no support on elimination or on falsification, and as convergent if the criterion is diminished support on elimination or on falsification. Such blanket classifications obscure the difference between, say, an inference from a conditional and its consequent to its antecedent on the one hand, and an inference to some recommendation on the basis of two distinct irrelevant considerations on the other hand. Intuitively, the first of these arguments is linked and the second convergent, but all the semantic tests mentioned classify both arguments the same way, either counting both as linked or counting both as convergent.

In contrast, Freeman's syntactic test does not presuppose support by the premisses being tested for linkage. The argument's rule or rules of inference are those implicitly used by the arguer, and need not be sound. An argument that fallaciously affirms the consequent has a mediating element in its rule of inference, namely, the variable ' $q$ ' in the rule: from "if $p$ then q" and $q$, you may infer $p$. Hence the premisses are linked. If on the other hand an arguer appeals to two quite different sorts of considerations in support of some course of action A, then the arguer is using a rule of inference with no mediating element: from "A has feature $\mathrm{x}$ " and "A has feature $\mathrm{y}$," you may infer "A should be done." Hence the premisses are convergent, even if in fact features $\mathrm{x}$ and $\mathrm{y}$ are each totally irrelevant to whether $\mathrm{A}$ should be done. Freeman's test thus classifies the two arguments differently, in just the way that we would intuitively classify them.

A further merit of Freeman's test is that, as shown by the examples of affirming the consequent and appealing to irrelevant considerations, it is often quite unproblematic to identify the rule of inference on which an arguer relies in drawing a conclusion from two or more premisses. Freeman (2011, pp. 175183) provides extensive guidelines for identifying such rules, drawing on the work of Hitchcock (1985) on enthymemes and extending it to qualified rules of inference, and has developed these guidelines even further in his (forthcoming).

Freeman's criterion also deals in a satisfactory way with the challenge to the alleged exhaustiveness of the linkedconvergent distinction posed by what Mark Vorobej (1995,

(C) David Hitchcock. Informal Logic, Vol. 35, No. 1 (2015), pp. 1-31. 
2006) calls "hybrid arguments." In hybrid arguments an independently relevant reason is "supplemented" by a set of premisses that in themselves are not relevant to the conclusion but that make the support for the conclusion stronger. An example is the following argument, invented by Vorobej:

(6) All the ducks that I've seen on this pond are yellow. I've seen all the ducks on this pond. Therefore, all the ducks on this pond are yellow.

On Vorobej's account the first premiss by itself provides some support for the conclusion. The second premiss is not independently relevant to the conclusion, but its addition to the argument raises the strength of support provided by the first premiss so that the argument becomes deductively valid.

In response, Freeman notes that the argument as stated has the form of a first-figure Aristotelian categorical syllogism in the mood Barbara, with 'yellow' as the major term P, 'ducks on this pond that I've seen' as the middle term M, and 'ducks on this pond' as the minor term S. Since Barbara is a valid form of argument, there is every reason to identify as the argument's warrant the rule corresponding to Barbara: from "all $\mathrm{M}$ are $\mathrm{P}$ " and "all S are M," you may infer "all S are P." This rule has the mediating element M, so on Freeman's criterion the argument is linked. The fact that the first premiss by itself offers some support for the conclusion is irrelevant to determining the argument's structure, and should be ignored in diagramming the argument. Similarly, five of Vorobej's six other examples of supposed hybrid arguments (those he labels as H, I, J, K, and L) are quite naturally construed as having a single rule of inference with a mediating element, and thus as being linked on Freeman's criterion. Vorobej's remaining example is the following somewhat artificial argument:

(7) My duck is yellow. Almost without exception, yellow ducks are migratory. My duck is no exception to any rule. [Therefore-DH] my duck migrates. (Vorobej 1995, p. 292)

The third premiss, which Vorobej classifies as supplementing the first two premisses, Freeman analyzes as a "counterrebuttal," a denial that the case at hand is an exception to an asserted defeasible generalization. On this analysis, it is not a premiss, and would be diagrammed as blocking any potential

(C) David Hitchcock. Informal Logic, Vol. 35, No. 1 (2015), pp. 1-31. 


\section{David Hitchcock}

rebuttal rather than as directly offered in support of the conclusion.

Freeman's well-supported analyses of Vorobej's invented examples indicate the plausibility of his appeal to an argument's inference rule or rules as the basis for determining its structure.

To sum up: Freeman's syntactic test has at least four merits. (1) It avoids the repetition implicit in semantic tests for linkage. (2) It gives intuitively correct results when applied to arguments with bad inferences. (3) It is often readily applicable. (4) It avoids the need to postulate hybrid arguments that are neither linked nor convergent.

Despite these advantages, Freeman's syntactic account of linkage has a number of limitations. (1) It is sometimes ambiguous what inference rule or rules an arguer is using to draw a conclusion. (2) Identification of an argument's inference rule or rules often requires an appeal to inferential plausibility, which thus erodes the sharp separation that Freeman posits between analysis and evaluation. (3) Freeman's criterion classifies as convergent many intuitively linked arguments. (4) On the other hand, it classifies as linked some arguments that are not decisively refuted if one premiss is refuted. (5) A reason can be independently relevant to a conclusion even if no inference rule licenses drawing the conclusion from it.

The following sections of this article discuss in turn each of these limitations, as well as an objection by Goddu (2007, 2009) that an argument's form does not necessarily determine what needs to be refuted in order to refute the argument.

\section{Ambiguity of an argument's inference rule or rules}

Arguers and reasoners rarely specify the inference rules in accordance with which they draw their conclusions. Since Freeman's criterion for linkage is a feature of an argument's inference rule, its application therefore requires interpretation of the argumentative text. In some cases variant interpretations are defensible, even to the extent that on one defensible interpretation of a single-inference argument the structure is entirely linked but on another it is convergent.

An example is the following invented argument:

(8) If either Fred is an uncle or Fred is a father, then Fred is male. Fred is an uncle. Fred is a father. So Fred is male.

(C) David Hitchcock. Informal Logic, Vol. 35, No. 1 (2015), pp. 1-31. 
(Bassham 2002, p. 72)

Bassham notes that, if either the second or the third premiss is omitted, the argument is still deductively valid. Hence, he concludes, any test based on suspension would classify the argument as convergent, with a partitioning into two independently relevant premiss-sets, one consisting of the first and second premisses and the other of the first and third premisses. But intuitively, Bassham thinks, the argument is linked. In reply, Freeman argues that the argument's inference license is the rule: from "if $p$ or $q$, then $r$ " and $p$ and $q$, you may infer that $r$. This rule has two mediating elements, namely, $p$ and $q$, so on his criterion the argument is linked, as it seems intuitively to be.

Has Freeman identified the inference rule correctly? Since Bassham's example is his own invention, produced merely as an example with no imagined context, it is hard to find any signals in it of its implicit rule of inference. Freeman falls back on his notion of an argument's mediating concepts. He notes that, if the second premiss is omitted, it is straightforward to identify as the mediating concept "Fred is a father." Similarly, if the third premiss is omitted, it is straightforward to identify as the mediating concept "Fred is an uncle." Hence "it would be best to say that" in the argument as stated both are mediating concepts (Freeman 2011, p. 150).

That may be a fair inference, but it does not follow that the argument's structure is linked. For one can take the mediating concepts to instantiate variables in two distinct rules of inference, one rule (from "if $p$ or $q$, then $r$ " and $p$, you may infer that $r$ ) licensing an inference from the first and second premiss to the conclusion, the other rule (from "if $p$ or $q$, then $r$ " and $q$, you may infer that $r$ ) licensing an inference from the first and third premiss to the conclusion. On this interpretation Freeman's criterion for linkage implies that the argument has a convergent structure, with two independently relevant reasons each consisting of two linked premisses.

This sort of ambiguity is not a decisive objection to Freeman's criterion. Freeman can simply accept the consequence that the implicit inference rule or rules in an argumentative text is sometimes indeterminate. The structure would then be linked on one attribution of the inference rule or rules and convergent on another. In such cases, it would make sense to attribute the inference rules that make the structure convergent, in case the argument is falsely taken to be refuted by the refutation of just

(C) David Hitchcock. Informal Logic, Vol. 35, No. 1 (2015), pp. 1-31. 


\section{David Hitchcock}

one of its premisses. In Bassham's example, neither the discovery that Fred is not an uncle nor the discovery that he is not a father should undermine the support for the conclusion that Fred is male.

\section{Need for inferential evaluation at the analysis stage}

Scholarly discussions of argument analysis commonly claim that it often requires evaluation. In particular, Claude Gratton (2002) has argued that determining whether an argument has linked or convergent structure may require preliminary evaluation of the comparative strength of support on each of these two possible analyses. His argument rests on the following example, which he adapts from a quotation commonly attributed to Albert Einstein:

(9) Knowledge is limited and imagination is almost limitless. So, imagination is more important than knowledge. (Gratton 2002, p. 10)

According to Gratton, in order to reach a well-supported judgment that this argument has a linked structure, one must notice that it is a stronger argument on this interpretation than if one interprets the structure as convergent, in which case the premisses of each of the two arguments would provide insufficient support. In reply, Freeman claims that on either of two possible interpretations the argument (modified to as to read as in example 4 above) comes out as linked on his criterion, without any need to evaluate the strength of support given by the premisses. On the first interpretation, the argument has an unexpressed premiss that, if $x$ is limited and $y$ is not limited, then $y$ is more important than $x$, with the mediating concept " $x$ is limited and $y$ is not limited." On the second interpretation, the argument has no unexpressed premiss and has as its inference rule: from ' $x$ is limited' and " $y$ is not limited," one may infer " $y$ is more important than $x$ "-which, Freeman claims, has the mediating element "limited." (This second interpretation is the one discussed in connection with example 4.)

Freeman's analysis is a bit loose, and Gratton admits to adapting the argument. Given the widespread quotation and misquotation of this argument in contemporary culture, it is worth looking at the original argument and its context. It is part 
of a quotation attributed to Einstein in a report of an interview with him that appeared in The Saturday Evening Post:

(10) [INTERVIEWER]: If we owe so little to the experience of others, how do you account for sudden leaps forward in the sphere of science? Do you ascribe your own discoveries to intuition or inspiration?

[EINSTEIN]: I believe in intuitions and inspirations. I sometimes feel that I am right. I do not know that I am. When two expeditions of scientists, financed by the Royal Academy, went forth to test my theory of relativity, I was convinced that their conclusions would tally with my hypothesis. I was not surprised when the eclipse of May 29, 1919, confirmed my intuitions. I would have been surprised if I had been wrong.

INTERVIEWER]: Then you trust more to your imagination than to your knowledge?

[EINSTEIN]: I am enough of the artist. to rely upon my imagination. Imagination is more important than knowledge. Knowledge is limited. Imagination encircles the world. (Viereck 1929, p. 117)

This reported conversation occurs towards the end of an extensive article reporting the content of a three-hour evening interview in Einstein's apartment in Berlin, at a time when there were no devices for recording such conversations. The absence of an audio recording is confirmed by the author's comment (Viereck 1929, p. 110) that he did not remember clearly Einstein's answer to his request to explain the fifth dimension. Further, the interview is likely to have taken place in German, given that both Einstein and the interviewer were native speakers of German and that the conversation took place in Berlin. Thus we are not reading the words Einstein spoke on that occasion, but a translation into English of what the interviewer reconstructed from memory (perhaps aided by notes) of their long conversation in German. Further, whatever Einstein said at the time, it was not a carefully thought out contribution to a publication, but an off-the-cuff remark at the end of a long conversation in the evening.

In the context as reported, Einstein is talking specifically about the relative importance of knowledge and imagination in the generation of new scientific hypotheses. He is not claiming that imagination is more important than knowledge for any purpose whatsoever. Further, the context indicates that he is picking

(C) David Hitchcock. Informal Logic, Vol. 35, No. 1 (2015), pp. 1-31. 


\section{David Hitchcock}

out knowledge and imagination from a universe of discourse limited to those mental states that play a role in the generation of new scientific hypotheses. It would be ridiculous to object to his inference that the moon also encircles the world, but is not more important than knowledge for the generation of scientific hypotheses. Thus the actual argument attributed to Einstein uses a quite circumscribed rule of inference: from "a mental state $x$ contributing to the generation of new scientific hypotheses is limited" and "a mental state $y$ contributing to the generation of new scientific hypotheses encircles the world," you may conclude " $y$ is more important than $x$ for the generation of new scientific hypotheses."

Freeman is correct that this rule of inference can be identified without first comparing the strength of support on this analysis to the strength of support if the text is taken to involve two independently relevant premisses. Indeed, any inference of a strict well-ordering $\mathrm{R}$ (i.e. a relation appropriately symbolized by ' $<$ ' or ' $>$ ') between two things from their possession of distinct properties $F$ and $G$ obviously uses the rule: from " $x$ is $F$ " and " $y$ is G," one may infer "xRy." For example, an inference that $a$ is taller than $b$ from $a$ 's being five feet six inches tall and $b$ five feet five inches tall uses the rule: from " $\mathrm{x}$ is five feet six inches tall" and " $y$ is five feet five inches tall," one may infer " $x$ is taller than y." Such comparative judgments based on independent facts about two things need both facts for their support. There is no need to consider the strength of support given to the comparative judgment by each fact separately in order to determine that the argument has a single rule of inference.

On the other hand, Freeman is mistaken in holding that on his second interpretation the rule of inference in Einstein's argument has a mediating element as Freeman defines it. For, as previously argued, any mediating element in a rule of inference must be a variable, but the word 'limited' in the rule that Freeman attributes to the argument is a constant, not a variable. The appearance of the word 'limited' in both premisses of Freeman's postulated rule of inference is purely accidental; the reasoning does not hinge on this fact, as we can see for example by noticing that there is no such repeated constant in the rule that licenses the inference in the argument attributed to Einstein in Viereck's article.

The concept of being limited would be a mediating concept in the argument if the argument had as its rule of inference: from " $x$ is $F$ " and " $y$ is not $F$," one may infer " $y$ is more im-

(C) David Hitchcock. Informal Logic, Vol. 35, No. 1 (2015), pp. 1-31. 
portant than x." But this rule of inference is obviously unsound, since it would allow one to draw incompatible conclusions from two arguments, each with premisses known to be true. For example, it is known that snow is white and coal is not white, and it is known that coal is black and snow is not black. The rule would allow us to infer from the first pair of known facts that coal is more important than snow and from the second pair that snow is more important than coal. Quite apart from the absurdity of these two inferences considered separately, the incompatibility of the two conclusions, each drawn in accordance with the suggested rule from premises known to be true, is strong reason not to attribute the rule to the author of the argument-Albert Einstein, who was no fool.

Thus in this respect, though not in the respect claimed by Gratton, the argument on Freeman's second interpretation does require inference evaluation in order to determine what rule of inference to attribute to the argument. Oddly, on this interpretation its structure comes out to be convergent rather than linked on Freeman's criterion, since there is no mediating element in its rule of inference. On Freeman's first interpretation, in which the argument is taken to be incomplete, with the unexpressed premiss that, if $\mathrm{x}$ is limited and $\mathrm{y}$ is not limited, then $\mathrm{y}$ is more important than $\mathrm{x}$, the argument comes out to be linked on Freeman's criterion. It also comes out as linked on that criterion if one adopts the strategy of Hoffmann's AGORA software (http://agora.gatech.edu/) of treating every single-inference argument as having as an unstated premiss (an "enabler") its "associated conditional" (Hitchcock 1985), i.e. the material conditional whose antecedent is the conjunction of the stated premisses and whose consequent is the stated conclusion. Indeed, if one follows either strategy for all single-inference arguments (i.e. either treating as an unstated premiss a covering generalization or treating as an unstated premiss the associated conditional), all multi-premiss single-inference arguments come out linked on Freeman's criterion. In that case, there would be no such thing as a convergent argument structure.

Just as Einstein's argument on Freeman's second interpretation needs inference evaluation in order to specify the variables in its rule of inference, so other arguments need inference evaluation for ascription of an inference rule. In particular, an inference rule with a variable that ranges over individuals, kinds, properties or relations needs specification of the scope of that range, i.e., of the universe of discourse. With the argument

(C) David Hitchcock. Informal Logic, Vol. 35, No. 1 (2015), pp. 1-31. 


\section{David Hitchcock}

attributed to Einstein, the context provided a sufficient basis for specifying this universe as the universe of mental states. But often context is not enough, so that attributing a determinate rule of inference, as Freeman's approach requires, must rely on considerations of inferential plausibility. For example, in the commonly advanced argument that marijuana should be legalized, because it is no more harmful than alcohol, which is already legal, there is indeterminacy over the scope of the variables of which "marijuana" and "alcohol" are values (Hitchcock 1985). Considerations of inferential plausibility make it reasonable to restrict the universe of discourse to psychotropic recreational drugs rather than (for example) to consumable substances in general.

If one distinguishes argument identification from argument analysis and accepts Freeman's tri-partite account of the components of a single-inference argument, then one should take these examples to show that it is argument identification rather than argument analysis that sometimes requires preliminary inference evaluation. In any case, inference evaluation sometimes must precede the final stage of argument evaluation.

\section{Identification as convergent of arguments that are intui- tively linked}

Einstein's argument and its variant misquotations come out as convergent on Freeman's criterion (unless they are assumed to have an unstated premiss). So do all parallel arguments that have a rule of inference of the form: From " $x$ has property F" and " $y$ has property $G$ " you may infer " $x$ is more $H$ than $y$ " (where $\mathrm{F}, \mathrm{G}$ and $\mathrm{H}$ are constants in the specific rule of inference, and ' $\mathrm{H}$ ' is an adjective taking a comparative). Such arguments are intuitively linked, since they satisfy the corollary that Freeman draws about linked structures: showing either premiss false refutes the argument. They thus join several other classes of arguments that Freeman counts as convergent even though intuitively they are linked. For example, on Freeman's criterion of linkage, conjunction introductions are convergent, because there is no mediating element in the rule of conjunction introduction: from $p_{1}$ and $\ldots$ and $p_{\mathrm{n}}$, one may infer " $p_{1}$ and $\ldots$ and $p_{\mathrm{n}}$." Freeman quite explicitly claims (2011, pp. 133-134) that such arguments have a convergent structure, in which each premise is independently relevant to the conclusion, although insufficient by

(C) David Hitchcock. Informal Logic, Vol. 35, No. 1 (2015), pp. 1-31. 
itself to establish it. But conjunction introductions seem like paradigm cases of linked arguments, since their premisses collectively entail the conclusion but generally no proper subset of them entails it. In fact, refutation of just one premiss of a conjunction introduction not only deprives the conclusion of support but also shows that the conclusion is false. Similarly Freeman classifies inductive generalizations as convergent, since again there is no mediating element in the rule of inductive generalization: from " $x_{1}$ is $\mathrm{S}$ and $x_{1}$ is $\mathrm{P}$ " and ... and " $x_{\mathrm{n}}$ is $\mathrm{S}$ and $x_{\mathrm{n}}$ is $\mathrm{P}$," you may infer "all S is $\mathrm{P}$ " $(2011$, pp. 133, 136). Here too Freeman is ready to say that each premiss of such an argument is independently relevant, even though refutation of any one of the premisses is enough to show that the conclusion is false. Of course, Freeman is at liberty to stick to his clear criterion and dismiss our intuitive judgments of particular arguments as a reflection of the theoretical confusion about the linked-convergent distinction. But, if the main point of identifying an argument as linked at the analysis stage is to simplify the work of evaluation by flagging cases where refutation of just one premiss is enough to refute the argument, as Freeman seems to think, then his criterion is under-generating such cases.

\section{Retrievability of some linked arguments with a refuted premiss}

Freeman takes any linked argument to be refutable by refuting any one of its premisses. But there may be a sound rule of inference for an argument with a refuted premiss that Freeman's criterion counts as linked. The argument as presented may fail, but it may be appropriate for an evaluator to go on to explore what can be made out of the argument once the suspect premiss is rejected. Such further exploration is indicated for any argument with an intuitively redundant premiss, such as Bassham's example ( 8 above). Although that particular argument could also be construed as convergent on Freeman's criterion, the same is not true of variants of Bassham's argument that use a single premiss to mark supposed satisfaction of two disjuncts. Such arguments come out linked on Freeman's criterion but do not fail irreparably if the premiss in question is refuted. Consider the following fictional conversation between a college student and an academic advisor:

(C) David Hitchcock. Informal Logic, Vol. 35, No. 1 (2015), pp. 1-31. 
(11) STUDENT: I would like to take the intermediate logic course.

ADVISOR: Well, the pre-requisite is either credit in the introductory logic course or enrolment in level 3 or 4 of a philosophy program. You meet both these requirements, so you may take the course.

STUDENT: Actually I am still in level 2.

ADVISOR: I see. So my argument that you may take the course does not work.

The advisor's final statement seems ridiculous in the circumstances, and it would seem pedantic for the advisor to go on to say that the conclusion still holds, since a modified version of the argument works. A more natural response would be to say something like: "Well, either of the two requirements is enough, so you may still take the course." It is a nice question whether such a response amounts to replacing the original argument with a new one or to taking the original argument to have a convergent structure with two inference rules. The latter interpretation does not seem impossible. Even on the former interpretation, evaluation of the argument is not finished once one notices the falsehood of a premiss required by the inference rule. One needs to consider the force of the argument once that premiss is rejected as false and replaced by the relevant truth. For any such modified argument, as in the present example, there may well be a sound rule of inference .

A similar point can be made with reference to Vorobej's invented argument ( 6 above) that all the ducks on a particular pond are yellow. Discovery that the second premiss is false (i.e., I have not in fact seen all the ducks on this pond) may refute the argument, construed as a triple with an inference rule as well as two premisses and a conclusion. However, in certain contexts and for certain purposes, it may make sense to go on to consider how well a revised version of that argument, with an accurate replacement for its false second premiss, supports the conclusion. Similarly for other cases where on Freeman's analysis Vorobej's supposedly supplementing premiss is rather part of a linked structure.

Thus the refutation of a single premiss in a structure that is linked on Freeman's criterion is not always sufficient to show that the argument with linked premisses is worthless.

(C) David Hitchcock. Informal Logic, Vol. 35, No. 1 (2015), pp. 1-31. 


\section{Independently relevant reasons not licensed by an infer- ence rule}

Freeman takes himself to be using a relevance criterion for determining whether an argument has convergent or linked structure: he takes each premiss of a linked argument to answer the question why one of the other premisses is relevant. Further, he faults other authors for advancing criteria for linkage that confuse the issue of relevance with the issue of strength of support. A linked premiss, he maintains, is distinguished not by the fact that it increases the strength of support given by the premiss or premisses to which it is linked but by the fact that it can be construed as an answer to the question about another premiss, "Why is that relevant?" (Freeman 2011, pp. 96, 100-101).

Relevance is a vexed concept, whose explication has proved difficult. Paul Grice, for example, expressed the hope in his 1967 William James lectures of addressing a number of problems with the conversational maxim "Be relevant" (Grice 1989, p. 27), but never did so. Freeman is content to say that he means probative relevance, formulated as Douglas Walton does in terms of one proposition giving "some reason, justification or basis" for proving another (Walton 1996, p. 113; quoted in Freeman 2011, p. 129). People make judgements of probative relevance intuitively and immediately, Freeman thinks, in the light of their stock of inferential habits, as described by Peirce:

A judgment is formed; and under the influence of a belief-habit this gives rise to a new judgment, indicating an addition to belief. Such a process is called an inference; the antecedent judgment is called the premiss; the consequent judgment, the conclusion; the habit of thought, which determined the passage from the one to the other (when formulated as a proposition), the leading principle. (Peirce 1955/1880, p. 130; partially quoted in Freeman 2011 , p. 130; italics in original)

On Freeman's account, people intuitively judge a proposition to be probatively relevant to another proposition if they are inclined as a matter of habit to infer a proposition of the second kind from a proposition of the first kind. For example, one intuitively takes the appearance of smoke in a particular situation to be probatively relevant to the existence of fire in that situation, in the light of one's habit of inferring the presence of fire from the appearance of smoke. This conception of relevance, Free-

(C) David Hitchcock. Informal Logic, Vol. 35, No. 1 (2015), pp. 1-31. 


\section{David Hitchcock}

man emphasizes (2011, pp. 131-132), is syntactic rather than semantic, since it appeals to a set of rules of inference rather to actual support of a conclusion by a premiss. It can be made objective by relativizing it to a canonical set of rules of inference rather than to the inferential habits of a particular individual (Freeman 2011, pp. 130-131).

Freeman's explication of probative relevance in terms of inference rules is questionable. A reason may be independently relevant to a conclusion even if no sound rule of inference licenses drawing the conclusion from it, even in a qualified way. For example, if one is looking to buy a car, being able to afford one that is for sale counts in favour of buying it, but it is not a sound rule of inference that, from " $x$ is looking to buy a car" and "x can afford to buy car $y$ " one may infer "other things being equal, x should buy car y." Further, it is implausible to attribute this rule to someone who cites the affordability of a particular car as a point in its favour.

Further, Freeman's account of probative relevance in terms of inference rules has the odd consequence that, in any convergent structure, there are two layers of inference rulesone consisting of the inference rules in virtue of which each reason is presented as independently relevant to the conclusion, the other consisting of the rule in virtue of which the reasons taken together are presented as providing sufficient support to the conclusion. Freeman holds that there is one inference from the convergent reasons taken together to the conclusion. Why then should we posit an inference from each convergent reason separately to the conclusion? Consider for example an argument from two premisses to their conjunction. On Freeman's analysis, this argument has a convergent structure. Each premiss, he thinks, is independently relevant to the conjunction of the two premisses. But does that mean that there is a sound inference rule from each premiss by itself to the conclusion? The following rule seems problematic: from $\mathrm{p}$, one may infer, ceteris paribus, "p and q."

One way to accommodate these two objections is to relax the concept of an inference rule so as to allow the conclusion to be qualified by a phrase like 'there is a reason for thinking that'. But this qualifier simply baptizes the claim that the reason is independently relevant to the conclusion, without giving a criterion for relevance.

Some other account seems required of the independent relevance of a reason in a convergent structure

(C) David Hitchcock. Informal Logic, Vol. 35, No. 1 (2015), pp. 1-31. 


\section{Goddu's objection}

Geoff Goddu $(2007,2009)$ has objected that an argument's form does not determine which premisses need to be refuted in order to refute the argument. Consider, he writes, the following argument:

(12) The die is red; the die shows an odd number; so the die is a cube.

He describes three situations, differing with respect to the universe of dice from which the die in question has been selected. He claims that in the first situation refutation of either premiss suffices to refute the argument, but that refutation of the argument requires refutation of both premisses in the second situation and of the first premiss in particular in the third, and that it is possible to construct a fourth situation in which refutation of the argument requires refutation of the second premiss. Thus, Goddu concludes, we can have a single form of argument with differing consequences of what premisses need to be refuted to refute the argument, depending on the situation in which arguments of that form are advanced.

If one takes Goddu's example to be in no need of an unexpressed premiss supplied by the context, it is no objection to Freeman's criterion for linkage. For the argument has no mediating concept, i.e., no concept common to the two premisses but missing from the conclusion that could be regarded as instantiating a variable in the argument's implicit rule of inference. Hence on Freeman's criterion the argument has a convergent structure. It is most reasonably construed as using the implicit rule of inference: given that die $x$ is red and die $x$ shows an odd number, you may conclude that die $x$ is a cube. In some situations, given a restriction on the universe of discourse to which the variable $x$ is relative, that rule of inference might be sound. Since the only variable in that rule of inference occurs in both the premisses and the conclusion, the structure is convergent. But nothing follows from its convergent structure about what premisses need to be refuted to refute the argument. It is only for linked structures that Freeman claims that the form determines what needs to be refuted to refute the argument.

(C) David Hitchcock. Informal Logic, Vol. 35, No. 1 (2015), pp. 1-31. 


\section{Seriousness of the limitations of Freeman's criterion}

Thus Freeman's criterion for linkage has a number of limitations: ambiguity of some arguments' inference rules, need to consider inferential plausibility in deciding what inference rule to attribute to an argument, classification as convergent of many intuitively linked arguments, potential cogency of some linked arguments with a refuted premiss, independently relevant reasons with no corresponding inference rule.

Collectively, how serious are these limitations?

Freeman needs to acknowledge that in practice there cannot be a sharp separation between the analysis of an argument and its evaluation. Considerations of inferential plausibility sometimes need to enter into the decision as to what rule or rules of inference to attribute to an argument. Sometimes, too, alternative analyses are defensible, even to the extent that on one analysis of its inference rules an argument has a convergent structure and on another analysis a linked structure. These qualifications of Freeman's position, however, do not undermine his contention that one can, in general, identify a linked structure using his criterion without subjecting the argument being analyzed to semantic tests of the strength of support given by the premisses in certain hypothetical circumstances.

There seems however to be something fundamentally unsatisfactory about taking the presence of a mediating element in a multi-premiss rule of inference as the basis for marking out a class of multi-premiss single-inference arguments in which refutation of just one premiss refutes the argument. The criterion of a mediating element under-generates this sort of vulnerability, because it fails to identify it in arguments where it is obvious, such as conjunction introductions and inductive generalizations. And it encourages premature dismissal of some arguments that satisfy the criterion for linkage, but that even with a refuted premiss can be redeemed with an adjustment of the argument's rule of inference to accommodate the replacement for the refuted premiss.

There is something odd, too, about construing independent relevance of a reason as the existence of a sound rule of inference that licenses drawing the conclusion from that reason. Some reasons seem to be independently relevant, for example to making a certain decision, even though no sound rule of inference licenses making that decision on the basis of that reason

(C) David Hitchcock. Informal Logic, Vol. 35, No. 1 (2015), pp. 1-31. 
alone. Further, on Freeman's construal of relevance as a function of a rule of inference, arguments with convergent structure rather oddly turn out to have nested rules of inference: one rule for each reason presented as independently relevant, plus a higher-order rule for the reasons taken collectively. There is thus reason to doubt Freeman's account of probative relevance in terms of inference rules.

\section{Summary}

Stephen Thomas introduced in his (1977) a distinction between so-called "convergent" reasoning where two or more independently relevant reasons are offered in direct support of a conclusion and so-called "linked" reasoning where two or more premisses work together to support a conclusion directly. Proposed criteria for linked structure based on the strength of support for the conclusion when a premiss is assumed to be false or absent have turned out to be subject to counter-examples. In contrast to these semantic approaches, James Freeman (2011) has developed a syntactic criterion for linkage, which he takes to be identifiable in an argument prior to its evaluation and to imply that refutation of any premiss in a linked structure suffices to refute the argument with that structure. His criterion assumes a tripartite conception of a single-inference argument as consisting not only of its premisses and its conclusion but also of a rule of inference that the arguer takes to license the inference from premisses to conclusion. A linked structure, Freeman holds, is constituted by a multi-premiss single-inference argument whose rule of inference has a "mediating element," a variable occurring in more than one premiss but not occurring in the conclusion. The mediating element or elements in the rule of inference link the premisses together.

Freeman's syntactic criterion has a number of advantages. Identifying an argument's rule of inference is often straightforward, and arguments whose rule of inference has a mediating element are intuitively linked. Given his tripartite conception of the components of an argument, Freeman is correct that refutation of just one premiss in a linked structure suffices to refute the argument. Unlike semantic criteria for linkage, Freeman's syntactic criterion is readily applicable to arguments with bad inferences. In straightforward cases, it has the advantage he claims for it of saving effort when one evaluates an argument

(C) David Hitchcock. Informal Logic, Vol. 35, No. 1 (2015), pp. 1-31. 


\section{David Hitchcock}

that one has identified as having linked structure.

But the criterion also has a number of limitations. One cannot maintain as sharp a separation as Freeman wishes between argument analysis and argument evaluation, but must appeal sometimes to considerations of inferential plausibility in deciding what rule of inference to attribute to an argument. When one does so, there can still be indeterminacy or ambiguity about an argument's rule of inference, even to the extent that it can be defensibly interpreted either as having rules that imply a convergent structure or as having rules that imply linked structure. Further, if one follows Freeman in taking as the primary justification for making the linked-convergent distinction the economy of effort in evaluation once a linked structure is identified, Freeman's criterion seriously under-generates cases where refutation of just one premiss suffices to refute a singleinference argument. Whole classes of arguments with this vulnerability, such as all conjunction introductions and all inductive generalizations, come out as convergent on Freeman's criterion. Further, although an argument that is linked on Freeman's criterion is refuted if just one of its premisses is refuted, it is sometimes possible to rescue the refuted argument by adjusting the rule of inference.

Most seriously, it may be a mistake to construe probative relevance as a function of a rule of inference, since in some cases no sound rule of inference licenses drawing a conclusion from a reason that is independently relevant to it; further, convergent reasoning rather oddly turns out to have nested rules of inference.

Acknowledgements: I thank Michael Hoffmann and two anonymous reviewers for helpful comments on an earlier version of this article.

\section{References}

Bailin, S., and Battersby, M. (2010). Reason in the Balance: An Inquiry Approach to Critical Thinking. Toronto: McGrawHill Ryerson.

Bassham, G. (2002). Linked and independent premises: a new analysis. In: F.H. van Eemeren, J.A. Blair, C.A. Willard and A.F. Snoeck Henkemans (Eds.), Proceedings of the Fifth

(C) David Hitchcock. Informal Logic, Vol. 35, No. 1 (2015), pp. 1-31. 
Conference of the International Society for the Study of Argumentation (pp. 69-73), Amsterdam: Sic Sat.

Bolzano, B. (1972/1837). Theory of Science (R. George, Trans.). Oxford; Blackwell. German original first published in 1837 with the title Wissenschaftslehre.

Copi, I.M., and Cohen, C, (1990). Introduction to Logic, 8th edition. New York: Macmillan.

Eemeren, F.H. van, and Grootendorst, R. (1992). Argumentation, Communication, and Fallacies. Hillsdale, New Jersey: Lawrence Erlbaum Associates.

Ennis, R.H. (1996). Critical Thinking. Upper Saddle River, New Jersey: Prentice-Hall.

Fisher, A. (2001). Critical Thinking: An Introduction. Cambridge: Cambridge University Press.

Freeman, J.B. (1988). Thinking Logically: Basic Concepts for Reasoning. Englewood Cliffs, New Jersey: Prentice Hall.

Freeman, J.B. (1991). Dialectics and the Macrostructure of Arguments: A Theory of Argument Structure. Berlin and New York: Foris.

Freeman, J.B. (1993). Thinking Logically: Basic Concepts for Reasoning, second edition. Englewood Cliffs, New Jersey: Prentice Hall.

Freeman, J.B. (2011). Argument Structure: Representation and Theory. Argumentation Library Volume 18. Dordrecht: Springer.

Freeman, J.B. (forthcoming). Identifying the warrant of an argument. Forthcoming in the Proceedings of the Eighth International Conference on Argumentation, Amsterdam, July 14, 2014.

George, R. (1986), Bolzano's concept of consequence. The Journal of Philosophy 83, 558-564.

Goddu, G.C. (2007). Against making the linked-convergent distinction. In: F.H. van Eemeren, J.A. Blair, C.A. Willard and B. Garssen (Eds.), Proceedings of the Sixth Conference of the International Society for the Study of Argumentation (pp. 465-469), Amsterdam: Sic Sat.

Goddu, G.C. (2009). Against making the linked-convergent distinction. In: F.H. van Eemeren and B. Garssen (Eds.), Pondering on Problems of Argumentation (pp. 181-189, chap. 13), Dordrecht: Springer. Reprint with minor editorial changes of Goddu (2007).

Govier, T. (2010). A Practical Study of Argument, 7th edition. Belmont, Californis: Wadsworth.

(C) David Hitchcock. Informal Logic, Vol. 35, No. 1 (2015), pp. 1-31. 
Gratton, C. (2002). Common pedagogical weaknesses in critical thinking textbooks and courses. In: H.V. Hansen, C.W. Tindale, J.A. Blair, R.H. Johnson, and R.C. Pinto (Eds.), Argumentation and its Applications (pp. 1-19). Windsor, ON: Ontario Society for the Study of Argumentation. CD-ROM.

Grice, H.P. (1989) Studies in the Way of Words. Cambridge, Massachusetts: Harvard University Press.

Groarke, L.A., and Tindale, C.W. (2013). Good Reasoning Matters: A Constructive Approach to Critical Thinking. Don Mills, Ontario: Oxford University Press.

Hitchcock, D. (1985). Enthymematic arguments. Informal Logic 7, 83-97.

LeBlanc, J. (1998). Thinking Clearly: A Guide to Critical Reasoning. New York: W. W. Norton.

Peirce, C.S. (1955/1880). What is a leading principle? In: J. Buchler (Ed.), Philosophical Writings of Peirce (pp. 129134), New York: Dover. The chapter consists mainly of excerpts from an article originally published in 1880, with short additions from an article published in 1867 and from encyclopaedia entries published in 1902.

Pollock, J.L. (1993). The phylogeny of rationality. Cognitive Science 17, 563-588.

Pollock, J.L. (1995). Cognitive Carpentry: How to Build a Person. Cambridge, Massachusetts: MIT Press.

Reed, C., Walton, D., and Macagno, F. 2007. Argument diagramming in logic, law and artificial intelligence. The Knowledge Engineering Review 22, 87-109.

Selinger, M. (2014). Towards formal representation and evaluation of arguments. Argumentation 28, 379-393.

Thomas, S.N. (1977, 1981, 1986, 1997). Practical Reasoning in Natural Language. 1st through 4th editions. Englewood Cliffs, New Jersey: Prentice-Hall.

Toulmin, S.E. (1958). The Uses of Argument. Cambridge: Cambridge University Press.

Vaughn, L., and MacDonald, C. (2010). The Power of Critical Thinking. 2nd Canadian edition. Don Mills, Ontario: Oxford University Press..

Viereck, G.S. (1929) What life means to Einstein: An interview by George Sylvester Viereck. The Saturday Evening Post (26 Oct 1929), pp. 17, 110, 113, 114, 117.

Vorobej, M. (1995). Hybrid arguments. Informal Logic 17, 289296.

Vorobej, M. (2006). A Theory of Argument. Cambridge: Cam-

(C) David Hitchcock. Informal Logic, Vol. 35, No. 1 (2015), pp. 1-31. 
bridge University Press.

Walton, D. (1996). Argument Structure: A Pragmatic Theory. Toronto: University of Toronto Press.

(C) David Hitchcock. Informal Logic, Vol. 35, No. 1 (2015), pp. 1-31. 